\title{
Curcumae Longae Rhizoma and Saussureae Radix Inhibit Nitric Oxide Production and Cannabinoid Receptor 2 Down-regulation
}

\author{
TAKASHI TANIKAWA ${ }^{1}$, MASASHI KITAMURA ${ }^{2}$, YASUHIRO HAYASHI ${ }^{3}$, \\ TAKAMI YOKOGAWA ${ }^{2}$ and YUTAKA INOUE ${ }^{1}$ \\ ${ }^{1}$ Laboratory of Nutri-Pharmacotherapeutics Management, School of Pharmacy, \\ Faculty of Pharmacy and Pharmaceutical Sciences, Josai University, Saitama, Japan; \\ ${ }^{2}$ Laboratory of Pharmacognocy, School of Pharmacy, \\ Faculty of Pharmacy and Pharmaceutical Sciences, Josai University, Saitama, Japan; \\ ${ }^{3}$ Laboratory of Biological Chemistry, Faculty of Pharma-Science, Teikyo University, Tokyo, Japan
}

\begin{abstract}
Background/Aim: The cannabinoid 2 (CB2) receptor is an important regulator of immunoinflammatory responses. Crude drugs commonly used in Japanese traditional Kampo medicine have displayed anti-inflammatory effects; however, few studies have reported that these effects are mediated via CB2 receptor signaling. Therefore, this study aimed to elucidate CB2 receptor-related anti-inflammatory regulation in crude drugs. Materials and Methods: The ethanol extracts of 34 crude drugs listed in the Japanese Pharmacopeia were tested, and the inhibitory effects on lipopolysaccharide (LPS)-induced nitric oxide (NO) production were evaluated in murine macrophage RAW 264 cells. Results: The extracts of Curcumae Longae Rhizoma (dried rhizome of Curcuma longa) and Saussureae Radix (dried root of Saussurea lappa) significantly inhibited NO production and attenuated the LPS-induced decrease in CB2 receptor mRNA expression. Conclusion: Curcumae Longae
\end{abstract}

This article is freely accessible online.

Correspondence to: Takashi Tanikawa, Laboratory of NutriPharmacotherapeutics Management, School of Pharmacy, Faculty of Pharmacy and Pharmaceutical Sciences, Josai University, 1-1, Keyakidai, Sakado, Saitama 350-0295, Japan. Tel/Fax: +81 492718013, e-mail: tanikawa@josai.ac.jp; Masashi Kitamura, Laboratory of Pharmacognocy, School of Pharmacy, Faculty of Pharmacy and Pharmaceutical Sciences, Josai University 1-1, Keyakidai, Sakado, Saitama 350-0295, Japan. Tel/Fax: +81 492718021, e-mail: kitamura@josai.ac.jp

Key Words: Curcumae Longae Rhizoma, Saussureae Radix, nitric oxide, TLR4, CB2, RAW 264 cells.
Rhizoma and Saussureae Radix can modulate the CB2receptor-related anti-inflammatory regulation in macrophages.

Macrophages are widely distributed in various tissues and exhibit diverse functions. They play an essential role in development, homeostasis, and tissue repair, and are involved in various inflammatory diseases, including atherosclerosis, Crohn's disease, and fibrosis (1). Macrophages express Tolllike receptors (TLRs) that recognize microbe-specific components called pathogen-associated molecular patterns (2). TLRs recruit specific adaptor molecules, such as myeloid differentiation factor 88 and toll/interleukin-1 receptor domain-containing adapter inducing interferon- $\beta$. This leads to the activation of mitogen-activated protein kinases, nuclear factor kappa B (NF-kB), or interferon regulatory factors (3). Activated macrophages produce proinflammatory mediators including inducible nitric oxide synthase (iNOS) and nitric oxide (NO) (4), which is synthesized by iNOS using Larginine as a substrate.

The CB2 receptor is a plasma membrane G-proteincoupled receptor first identified in the spleen tissue (5). As they are mainly expressed in the somatodendritic compartment, and under pathological conditions, it was considered that $\mathrm{CB} 2$ receptors may modulate neuroprotective mechanisms in various mental and neurological diseases (6). CB2 receptors can also modulate immune cell function (7), and were reported to be highly expressed in peripheral immune tissues, including spleen $\mathrm{T}$ cells and macrophages $(8,9)$. In addition, CB2 receptor-deficient mice were found to have exacerbated inflammation (7). As CB2 receptor expression was reduced in lipopolysaccharide (LPS)stimulated RAW 264 cells (10) and microglia cells (11), factors that attenuate the reduction of $\mathrm{CB} 2$ receptors may be novel therapeutic regulators for inflammatory diseases. 


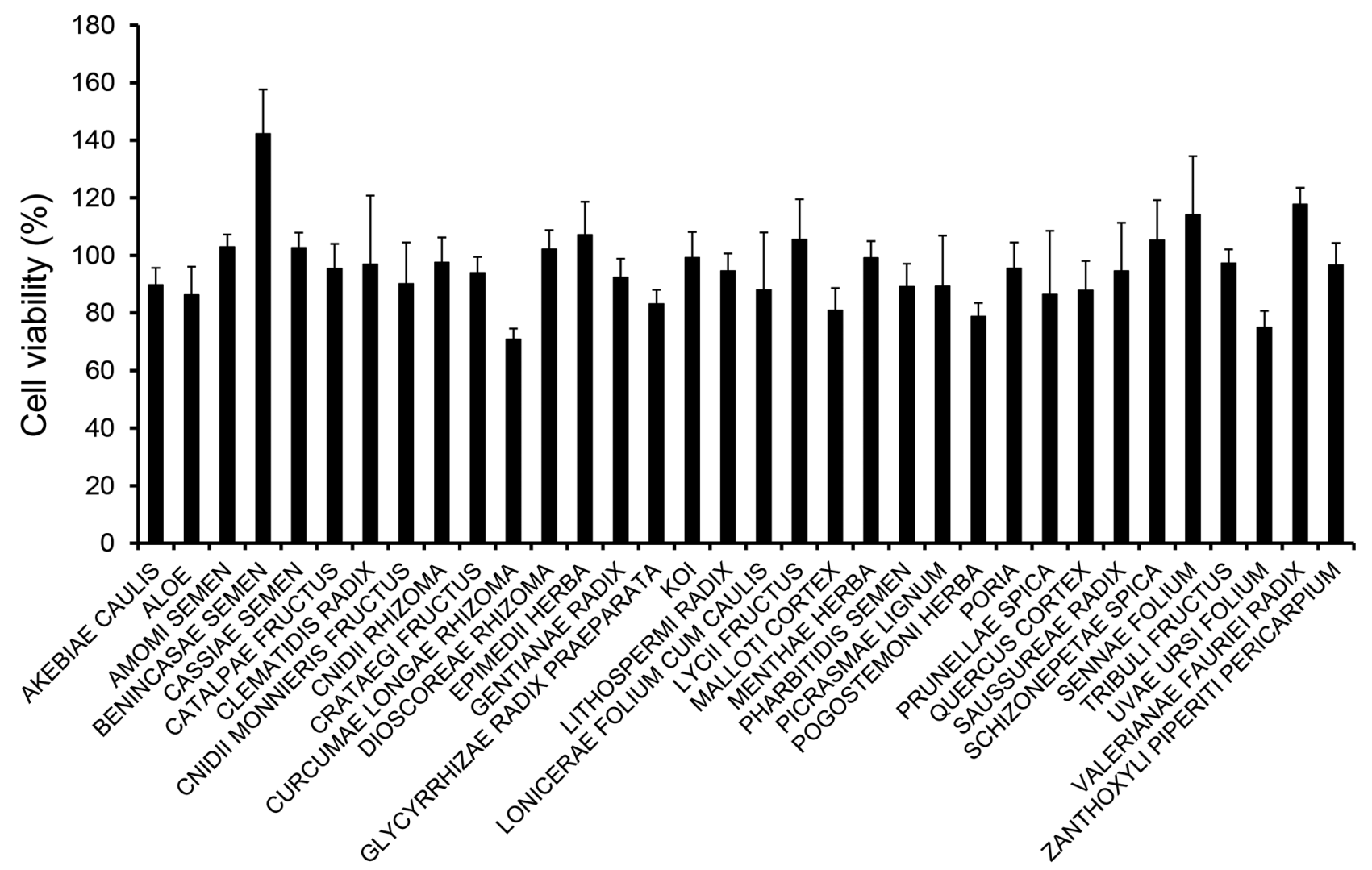

Figure 1. Effects of ethanol extracts on the viability of lipopolysaccharide (LPS)-stimulated RAW 264 cells. Cells were pretreated with the ethanol extracts of crude drugs for $0.5 \mathrm{~h}$ prior to incubation with LPS $(100 \mathrm{ng} / \mathrm{ml})$ for $24 \mathrm{~h}$. Cell viability was measured using the Cell Counting Kit-8 assay. Data are presented as the mean \pm standard deviation $(S D ; n=4)$.

Appropriate regulation of the immune system is very important for preventing diseases. Immune system dysfunction may be caused by aging, physical and mental stress, and an unhealthy lifestyle, resulting in the development of immunerelated conditions, including cancer, infectious disease, and allergy. Although several chemical medicines are available for the treatment of these conditions, most of them have detrimental side effects after prolonged use. Thus, natural products that exhibit significant anti-inflammatory activities have attracted considerable attention.

Traditional Kampo medicine is utilized in Japan as an alternative and complementary therapy for inflammation. For example, Forsythiae Fructus, derived from the fruits of Forsythia suspensa (Thunb.) Vahl, is traditionally used for its antiinflammatory, diuretic, and antiviral effects (12). Phellodendri Cortex, which originates from the dried trunk bark of Phellodendron amurense, has anti-inflammatory and antimicrobial activities (13). Experimental data also demonstrated that several crude drugs including those previously mentioned, inhibited LPS-induced inflammation in macrophages $(12,13)$. However, it remains unclear if the anti-inflammatory effects can be attributed to the CB2 receptor modulation.
In this study, we evaluated the anti-inflammatory effects and $\mathrm{CB} 2$ receptor expression of crude drugs using the mouse macrophage cell line, RAW 264 cells (10). LPS-stimulatedRAW 264 cells are frequently used to study macrophage function in inflammatory diseases (14). We demonstrated that $70 \%$ ethanolic extracts of Curcumae Longae Rhizoma and Saussureae Radix strongly suppressed NO production in macrophages. Curcumae Longae Rhizoma and Saussureae Radix originate from the rhizome of Curcuma longa and roots of Saussurea lappa, respectively. Furthermore, reduction in CB2 receptor mRNA levels due to LPS stimulation was attenuated by the extracts. The extracts of Curcumae Longae Rhizoma and Saussureae Radix showed anti-inflammatory effects and served as immunomodulators by regulating $\mathrm{CB} 2$ receptor expression.

\section{Materials and Methods}

Materials. Thirty-four crude drugs listed in the $17^{\text {th }}$ edition of the Japanese Pharmacopeia were selected and purchased from several distributors $(15,16)$. The samples were prepared as previously described (16). Briefly, crude drugs were refluxed in $70 \%$ ethanol 


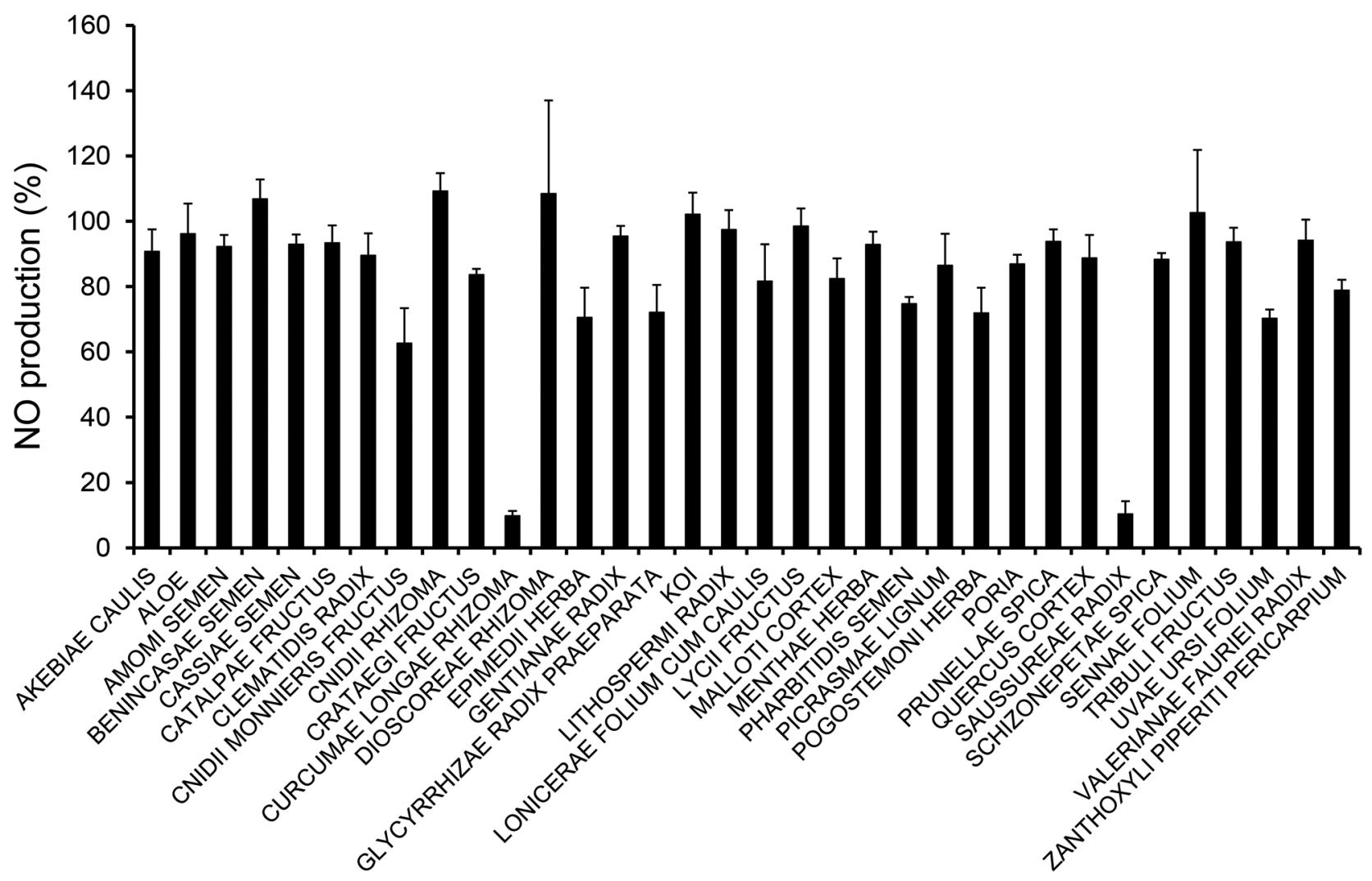

Figure 2. Effects of crude drug extracts on nitric oxide (NO) production in LPS-stimulated RAW 264 cells. Cells were pretreated with the ethanol extracts of crude drugs for $0.5 \mathrm{~h}$ prior to incubation with LPS (100 $\mathrm{ng} / \mathrm{ml})$ for $24 \mathrm{~h}$. The levels of NO in the culture medium were measured using Griess reaction. Data are presented as the mean $\pm S D(n=4)$.

for $1 \mathrm{~h}$, and the extracts were dried by evaporation. The samples were dissolved in dimethyl sulfoxide to a concentration of 10 $\mathrm{mg} / \mathrm{ml}$. ISOGEN II was purchased from Nippon Gene Co., Ltd. (Tokyo, Japan). FastGene Scriptase II cDNA Synthesis kit was purchased from Nippon Genetics Co., Ltd. (Tokyo, Japan). LPS from E. coli O111, Dulbecco's Modified Eagle Medium (DMEM; high glucose) without L-glutamine and phenol red, L-glutamine, MEM nonessential amino acids (NEAA), Eagle's minimum essential medium (EMEM) with L-glutamine and phenol red, $N$-1naphthylethylenediamine dihydrochloride, phosphoric acid, and sulfanilamide were purchased from FUJIFILM Wako Pure Chemical Corporation (Osaka, Japan). Foetal bovine serum (FBS) was purchased from Biowest (Nuaille, France).

Cell culture. RAW 264 cells were grown at $37^{\circ} \mathrm{C}$ in EMEM supplemented with $10 \%$ FBS, $1 \%$ NEAA, $100 \mathrm{U} / \mathrm{ml}$ of penicillin, and $100 \mu \mathrm{g} / \mathrm{ml}$ of streptomycin. For experiments, RAW 264 cells were plated in a 24- or 96-well flat-bottomed tissue culture plates containing DMEM without phenol red, supplemented with $0.5 \%$ FBS, $2 \mathrm{mM}$ L-glutamine, $100 \mathrm{U} / \mathrm{ml}$ of penicillin, and $100 \mu \mathrm{g} / \mathrm{ml}$ of streptomycin. The cells were cultured overnight at $37^{\circ} \mathrm{C}$ in a humidified atmosphere of $5 \% \mathrm{CO}_{2} / 95 \%$ air. The cells were then pretreated with various crude drug extracts for $0.5 \mathrm{~h}$ before stimulation with LPS. The cell culture supernatant was then collected via centrifugation. NO concentration in the cell culture supernatant was determined using the Griess reagent system. Briefly, the supernatant was mixed with an equal volume of Griess reagent $[2.5 \% \quad(\mathrm{v} / \mathrm{v})$ phosphoric acid containing $1 \% \quad(\mathrm{w} / \mathrm{v})$ sulfanilamide and $0.1 \%$ (w/v) $N$-1-naphthylethylenediamine dihydrochloride] for $20 \mathrm{~min}$ at room temperature. The absorbance was measured at $550 \mathrm{~nm}$ using a SpectraMax M2 spectrophotometer (Molecular Devices, LLC, San Jose, CA, USA). Cell viability was assayed using the Cell Counting Kit- 8 (Dojindo Laboratories, Kumamoto, Japan). Briefly, RAW 264 cells were treated with crude drug extracts and LPS, and the culture medium was removed. Culture medium and Cell Counting Kit- 8 reagent were added to each well and incubated for $2 \mathrm{~h}$ at $37^{\circ} \mathrm{C}$ in a humidified atmosphere of $5 \% \mathrm{CO}_{2} / 95 \%$ air. Absorbance was measured at $450 \mathrm{~nm}$ using a microplate reader (EMax, Molecular Devices, LLC.).

$R N A$ isolation and real-time reverse transcription polymerase chain reaction (RT-PCR) analysis. Total RNA was extracted using ISOGEN II according to the manufacturer's instructions and was reverse transcribed to cDNA using the FastGene Scriptase II cDNA Synthesis Kit. Real-time PCR was performed using Taq DNA Polymerase with Standard Taq Buffer (New England BioLabs, Ipswich, MA, USA) and EvaGreen (Biotium, Inc, San Francisco, CA, USA) with a Thermal Cycler Dice Real-Time System (Takara Bio Inc, Shiga, Japan). The primers used are as follows: mouse CB2: 5'-TCCTATCATTT ACGCCCTGC-3' (sense), 5'-CCTCTGACTCGGGCTGTTTC-3' 


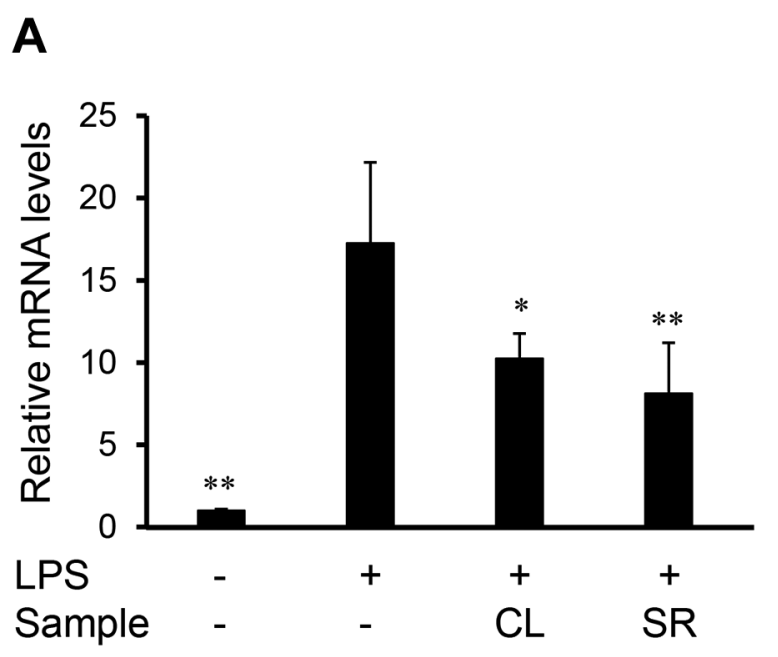

C

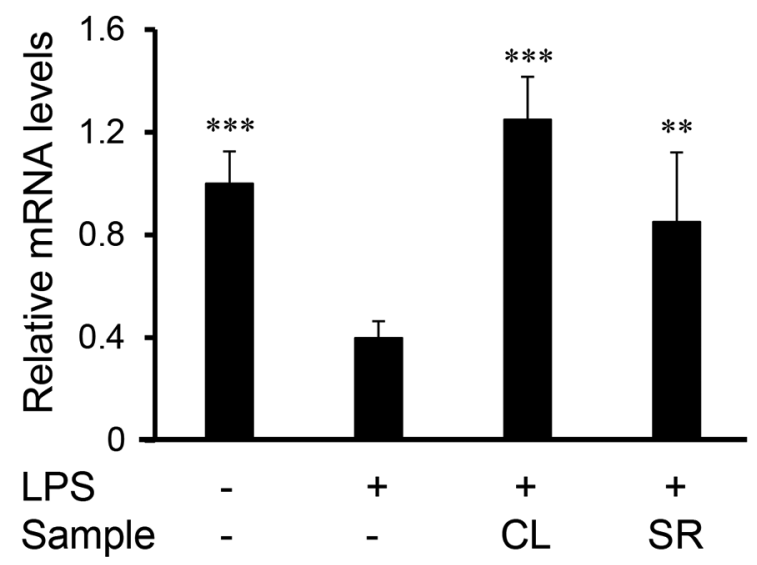

(antisense); mouse iNOS: 5'-TGGAGCCAGTTGTGGATTGTC-3' (sense), 5'-GGTCGTAATGTCCAGGAAGTAG-3' (antisense); mouse TLR4: 5'-CCTGACACCAGGAAGCTTGA-3' (sense), 5'TCAATTGTTTCAATTTCACACCTGG-3' (antisense); and mouse $\beta$ actin: 5' -CGGTTCCGATGCCCTGAGGCTCTT-3' (sense), 5'CGTCACACTTCATGATGGAATTGA-3' (antisense). The values obtained were normalized to $\beta$-actin mRNA levels. The $2^{-\Delta \Delta C_{t}}$ method was used to calculate the relative expression levels.

Statistical analyses. The significance of differences was analysed using Student's $t$-test by Microsoft Excel software (Microsoft Corporation, Seattle, WA, USA). Statistical significance was set at $p<0.05$.

\section{Results}

To evaluate anti-inflammatory effects, we first prepared 34 crude drug extracts (refluxed in $70 \%$ ethanol) at a final concentration of $10 \mu \mathrm{g} / \mathrm{ml}$ and examined their effects on the viability of LPS-induced RAW 264 cells. In the presence of

\section{B}

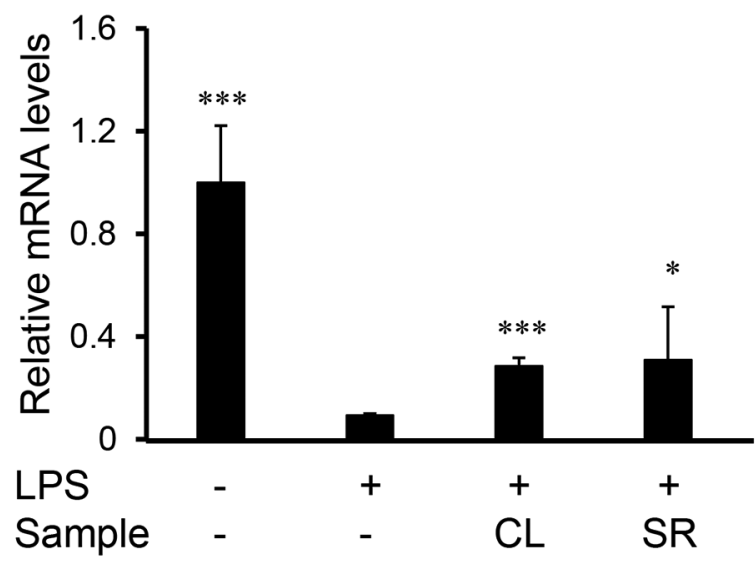

Figure 3. Effects of Curcumae Longae Rhizoma and Saussureae Radix on iNOS, TNF-a, TLR4, and CB2 receptor expression in LPS-stimulated $R A W 264$ cells. Cells were pretreated with the ethanol extracts of crude drugs for $0.5 \mathrm{~h}$ prior to LPS stimulation (100 $\mathrm{ng} / \mathrm{ml}$ for $8 \mathrm{~h}$ ). Total RNA was then isolated using the ISOGEN II. iNOS (A), CB2 receptor (B), and TLR4 (C) mRNA levels were analysed by real-time reverse transcription polymerase chain reaction. Relative mRNA levels were determined using the $C t$ value method and normalized to $\beta$-actin expression. Data are presented as the mean $\pm S D(n=3-4) .{ }^{*} p<0.05$, $* * p<0.01$, and $* * * p<0.001$ compared to the LPS-treated group.

crude drugs, cell viability in all samples was over $70 \%$, but was relatively low in the presence of Curcumae Longae Rhizoma (70.9 $\pm 3.7 \%)$, Pogostemoni Herba $(78.8 \pm 4.6 \%)$, and Uvae Ursi Folium (75.0 $55.7 \%)$ as shown in Figure 1. Next, we evaluated the effects on NO production in LPS-induced RAW 264 cells. Of the 34 crude drug extracts, NO production was suppressed by the addition of Curcumae Longae Rhizoma $(9.8 \pm 1.5 \%)$ and Saussureae Radix $(10.4 \pm 3.9 \%)$ (Figure 2). The rhizome of C. longa, also known as turmeric, has various therapeutic applications in inflammatory disorders and wound healing (17). Meanwhile, Saussureae Radix has long been used as a medicinal herb to treat various diseases of the digestive system. It has been reported that the ethanol extract of S. lappa suppressed inflammatory activity in an animal model induced by carrageenan (18).

Focusing on the two crude drugs, the mRNA levels of iNOS, TLR4, and CB2 receptor were measured using real-time RT- 
PCR (Figure 3A-C). The mRNA levels of iNOS in the LPSstimulated group were approximately 15 -fold higher than those in the non-stimulated group. LPS-stimulated iNOS expression was suppressed after treatment with Curcumae Longae Rhizoma (10-fold) and Saussureae Radix (approximately 8fold). The mRNA levels of TLR4 and CB2 receptors in LPSstimulated cells were lower than those in non-treated cells (Figure 3B and C). Both Curcumae Longae Rhizoma and Saussureae Radix extracts attenuated LPS-induced reduction in the mRNA of TLR4 and CB2 receptors. These results indicate that Curcumae Longae Rhizoma and Saussureae Radix inhibited NO production in macrophages and had antiinflammatory effects, which could be mediated by the mRNA expression of iNOS and TLR4, which are major inflammationrelated genes, as well as the mRNA levels of $\mathrm{CB} 2$ receptor.

\section{Discussion}

In this study, we evaluated 34 crude drugs listed in the Japanese Pharmacopeia. The inhibitory effects of crude drug extracts on NO production are listed in the Traditional Medical \& Pharmaceutical Database, Institute of Natural Medicine, University of Toyama (19). Using this information, we selected several crude drugs that exhibited inhibitory effects on NO production and compared them with Curcumae Longae Rhizoma and Saussureae Radix. We found that Curcumae Longae Rhizoma and Saussureae Radix significantly suppressed NO production (data not shown). Previous reports indicated that LPS-stimulated NO production in RAW 264 cells was inhibited by the constituents of Curcumae Longae Rhizoma and Saussureae Radix (20, 21). Over the decades, several studies have been conducted on the anti-inflammatory effects of C. longa (22). In RAW 264 cells, curcumin, curcumol, and turmeronol, which are major components of Curcumae Longae Rhizoma, inhibited LPSinduced NO production by suppressing iNOS mRNA expression $(20,23,24)$. S. lappa is commonly known as costus, and its dried root has been traditionally used for inflammatory diseases, including rheumatoid arthritis, gastritis, bronchitis, and asthma $(21,25,26)$. It has been reported that Saussureae Radix alleviated neuroinflammation in LPS-stimulated microglial cells via $\mathrm{HO}-1 / \mathrm{Nrf}-2$ induction (27). The main chemical constituents of S. lappa are sesquiterpenes and sesquiterpene lactones. Santamarin and dehydrocostuslactone, sesquiterpenes isolated from $S$. lappa, suppressed iNOS-derived NO production in RAW 264 cells $(21,28)$. However, CB2 receptor-mediated anti-inflammatory effects of the constituents have not been examined. A recent study demonstrated that $\mathrm{CB} 2$ receptor activation alleviated septic lung injury (29). In addition, it was postulated that both Curcumae Longae Rhizoma and Saussureae Radix may have related therapeutic effects. In our study, we showed that crude drug extracts of Curcumae Longae Rhizoma and Saussureae
Radix suppressed down-regulation of CB2 receptors in LPSinduced RAW 264 cells. Since the plants contain multiple bioactive compounds, the anti-inflammatory effect may be the result of multiple signaling pathways that are activated by various bioactive components. Further studies are necessary to elucidate the underlying mechanisms.

In conclusion, we screened the anti-inflammatory effects of 34 crude drugs listed in the Japanese Pharmacopeia and assessed whether they exert anti-inflammatory effects via CB2 receptor signaling. LPS-induced NO production in RAW 264 cells was significantly inhibited by the extracts of Curcumae Longae Rhizoma and Saussureae Radix. Treatment with these extracts attenuated LPS-induced changes in the mRNA levels of iNOS, TLR4, and CB2 receptor. These results indicate that $\mathrm{CB} 2$ receptor signaling can modulate the anti-inflammatory effects of the two crude drug extracts.

\section{Conflicts of Interest}

The Authors declare no conflicts of interest in relation to this study.

\section{Authors' Contributions}

Conceptualization and supervision: T.T.; Methodology: all Authors; Formal analysis: T.T. and M.K.; writing, original draft preparation: T.T. and M.K.; writing, review and editing: all Authors. All Authors have read and agreed to the final version of the manuscript.

\section{References}

1 Murray PJ and Wynn TA: Protective and pathogenic functions of macrophage subsets. Nat Rev Immunol 11(11): 723-737, 2011. PMID: 21997792. DOI: $10.1038 /$ nri3073

2 Akira S, Uematsu S and Takeuchi O: Pathogen recognition and innate immunity. Cell 124(4): 783-801, 2006. PMID: 16497588. DOI: $10.1016 /$ j.cell.2006.02.015

3 Kawasaki T and Kawai T: Toll-like receptor signaling pathways. Front Immunol 5: 461, 2014. PMID: 25309543. DOI: 10.3389/ fimmu.2014.00461

4 MacMicking J, Xie QW and Nathan C: Nitric oxide and macrophage function. Annu Rev Immunol 15: 323-350, 1997. PMID: 9143691. DOI: 10.1146/annurev.immunol.15.1.323

5 Munro S, Thomas KL and Abu-Shaar M: Molecular characterization of a peripheral receptor for cannabinoids. Nature 365(6441): 61-65, 1993. PMID: 7689702. DOI: 10.1038/365061a0

6 Onaivi ES, Ishiguro H, Gong JP, Patel S, Meozzi PA, Myers L, Perchuk A, Mora Z, Tagliaferro PA, Gardner E, Brusco A, Akinshola BE, Liu QR, Chirwa SS, Hope B, Lujilde J, Inada T, Iwasaki S, Macharia D, Teasenfitz L, Arinami T and Uhl GR: Functional expression of brain neuronal CB2 cannabinoid receptors are involved in the effects of drugs of abuse and in depression. Ann N Y Acad Sci 1139: 434-449, 2008. PMID: 18991891. DOI: 10.1196/annals.1432.036

7 Turcotte C, Blanchet MR, Laviolette M and Flamand N: The $\mathrm{CB}_{2}$ receptor and its role as a regulator of inflammation. Cell Mol Life Sci 73(23): 4449-4470, 2016. PMID: 27402121. DOI: 10.1007/s00018-016-2300-4 
8 Schatz AR, Lee M, Condie RB, Pulaski JT and Kaminski NE: Cannabinoid receptors $\mathrm{CB} 1$ and $\mathrm{CB} 2$ : a characterization of expression and adenylate cyclase modulation within the immune system. Toxicol Appl Pharmacol 142(2): 278-287, 1997. PMID: 9070350. DOI: 10.1006/taap.1996.8034

9 Galiègue S, Mary S, Marchand J, Dussossoy D, Carrière D, Carayon P, Bouaboula M, Shire D, Le Fur G and Casellas P: Expression of central and peripheral cannabinoid receptors in human immune tissues and leukocyte subpopulations. Eur J Biochem 232(1): 54-61, 1995. PMID: 7556170. DOI: 10.1111/ j.1432-1033.1995.tb20780.x

10 Carlisle SJ, Marciano-Cabral F, Staab A, Ludwick C and Cabral GA: Differential expression of the CB2 cannabinoid receptor by rodent macrophages and macrophage-like cells in relation to cell activation. Int Immunopharmacol 2(1): 69-82, 2002. PMID: 11789671. DOI: 10.1016/s1567-5769(01)00147-3

11 Pietr M, Kozela E, Levy R, Rimmerman N, Lin YH, Stella N, Vogel $\mathrm{Z}$ and Juknat A: Differential changes in GPR55 during microglial cell activation. FEBS Lett 583(12): 2071-2076, 2009. PMID: 19464294. DOI: 10.1016/j.febslet.2009.05.028

12 Pan X, Cao X, Li N, Xu Y, Wu Q, Bai J, Yin Z, Luo L and Lan L: Forsythin inhibits lipopolysaccharide-induced inflammation by suppressing JAK-STAT and p38 MAPK signalings and ROS production. Inflamm Res 63(7): 597-608, 2014. PMID: 24691777. DOI: 10.1007/s00011-014-0731-7

13 Choi YY, Kim MH, Han JM, Hong J, Lee TH, Kim SH and Yang WM: The anti-inflammatory potential of Cortex Phellodendron in vivo and in vitro: down-regulation of $\mathrm{NO}$ and iNOS through suppression of NF-kB and MAPK activation. Int Immunopharmacol 19(2): 214-220, 2014. PMID: 24503166. DOI: $10.1016 /$ j.intimp.2014.01.020

14 Heller RA, Schena M, Chai A, Shalon D, Bedilion T, Gilmore J, Woolley DE and Davis RW: Discovery and analysis of inflammatory disease-related genes using cDNA microarrays. Proc Natl Acad Sci U.S.A. 94(6): 2150-2155, 1997. PMID: 9122163. DOI: 10.1073/pnas.94.6.2150

15 The Ministry of Health, Labour and Welfare 2016: The Japanese pharmacopoeia. 17th edn (English version). The Ministry of Health, Labour and Welfare, Tokyo, Japan, 2016. Available at: https://www.mhlw.go.jp/file/06-Seisakujouhou-11120000Iyakushokuhinkyoku/JP17_REV_1.pdf [Last accessed on November 16, 2021]

16 Kiba Y, Oyama R, Misawa S, Tanikawa T, Kitamura M and Suzuki R: Screening for inhibitory effects of crude drugs on furin-like enzymatic activities. J Nat Med 75(4): 1080-1085, 2021. PMID: 33928494. DOI: 10.1007/s11418-021-01519-9

17 Ghosh S, Banerjee S and Sil PC: The beneficial role of curcumin on inflammation, diabetes and neurodegenerative disease: A recent update. Food Chem Toxicol 83: 111-124, 2015. PMID: 26066364. DOI: 10.1016/j.fct.2015.05.022

18 Gokhale AB, Damre AS, Kulkami KR and Saraf MN: Preliminary evaluation of anti-inflammatory and anti-arthritic activity of $\mathrm{S}$. lappa, A. speciosa and A. aspera. Phytomedicine 9(5): 433-437, 2002. PMID: 12222664. DOI: 10.1078/09447110260571689

19 Traditional Medical \& Pharmaceutical Database. University of Toyama. Available at: https://dentomed toyama-wakan.net/ index_en [Last accessed on November 15, 2021]

20 Kim KM, Pae HO, Zhung M, Ha HY, Ha YA, Chai KY, Cheong YK, Kim JM and Chung HT: Involvement of anti-inflammatory heme oxygenase- 1 in the inhibitory effect of curcumin on the expression of pro-inflammatory inducible nitric oxide synthase in RAW264.7 macrophages. Biomed Pharmacother 62(9): 630636, 2008. PMID: 18325727. DOI: 10.1016/j.biopha. 2008.01 .008

21 Choi HG, Lee DS, Li B, Choi YH, Lee SH and Kim YC: Santamarin, a sesquiterpene lactone isolated from Saussurea lappa, represses LPS-induced inflammatory responses via expression of heme oxygenase- 1 in murine macrophage cells. Int Immunopharmacol 13(3): 271-279, 2012. PMID: 22564506. DOI: $10.1016 /$ j.intimp.2012.04.016

22 Zhang HA and Kitts DD: Turmeric and its bioactive constituents trigger cell signaling mechanisms that protect against diabetes and cardiovascular diseases. Mol Cell Biochem 476(10): 37853814, 2021. PMID: 34106380. DOI: 10.1007/s11010-02104201-6

23 Chandrasekaran CV, Sundarajan K, Edwin JR, Gururaja GM, Mundkinajeddu D and Agarwal A: Immune-stimulatory and antiinflammatory activities of Curcuma longa extract and its polysaccharide fraction. Pharmacognosy Res 5(2): 71-79, 2013. PMID: 23798880. DOI: 10.4103/0974-8490.110527

24 Okuda-Hanafusa C, Uchio R, Fuwa A, Kawasaki K, Muroyama $\mathrm{K}$, Yamamoto $\mathrm{Y}$ and Murosaki S: Turmeronol A and turmeronol B from Curcuma longa prevent inflammatory mediator production by lipopolysaccharide-stimulated RAW264.7 macrophages, partially via reduced NF-kB signaling. Food Funct 10(9): 5779-5788, 2019. PMID: 31454011. DOI: 10.1039/ c9fo00336c

25 Pandey MM, Rastogi S and Rawat AK: Saussurea costus: botanical, chemical and pharmacological review of an ayurvedic medicinal plant. J Ethnopharmacol 110(3): 379-390, 2007. PMID: 17306480. DOI: 10.1016/j.jep.2006.12.033

26 Wang YF, Ni ZY, Dong M, Cong B, Shi QW, Gu YC and Kiyota $\mathrm{H}$ : Secondary metabolites of plants from the genus Saussurea: chemistry and biological activity. Chem Biodivers 7(11): 26232659, 2010. PMID: 21072766. DOI: 10.1002/cbdv.200900406

$27 \mathrm{Oh} \mathrm{YC,} \mathrm{Li} \mathrm{W} \mathrm{and} \mathrm{Choi} \mathrm{JG:} \mathrm{Saussureae} \mathrm{Radix} \mathrm{attenuates}$ neuroinflammation in LPS-stimulated mouse BV2 microglia via HO-1/Nrf-2 induction and inflammatory pathway inhibition. Mediators Inflamm 2021: 6687089, 2021. PMID: 33790692. DOI: $10.1155 / 2021 / 6687089$

28 Park EJ, Park SW, Kim HJ, Kwak JH, Lee DU and Chang KC: Dehydrocostuslactone inhibits LPS-induced inflammation by p38MAPK-dependent induction of hemeoxygenase-1 in vitro and improves survival of mice in CLP-induced sepsis in vivo. Int Immunopharmacol 22(2): 332-340, 2014. PMID: 25066549. DOI: $10.1016 /$ j.intimp.2014.07.012

29 Liu AP, Yuan QH, Zhang B, Yang L, He QW, Chen K, Liu QS, $\mathrm{Li} Z$ and Zhan J: Cannabinoid receptor 2 activation alleviates septic lung injury by promoting autophagy via inhibition of inflammatory mediator release. Cell Signal 69: 109556, 2020. PMID: 32027949. DOI: 10.1016/j.cellsig.2020.109556

Received October 16, 2021

Revised November 15, 2021

Accepted November 16, 2021 